Marko Pavlović ${ }^{1}$, Biljana Stojanović-Višić ${ }^{*}$, Marija Runić Ristić ${ }^{3}$

${ }^{1}$ PE Post of Serbia, Belgrade, Serbia

${ }^{2}$ Union - Nikola Tesla University, Faculty of Engineering Management, Belgrade, Serbia

${ }^{3}$ Union - Nikola Tesla University, Faculty of Management, Sremski Karlovci, Serbia

\title{
The Relationship between Workplace Conflicts and Job Satisfaction in the Public Sector in Serbia
}

DOI: 10.7595/management.fon.2021.0025

Abstract:

Research Question: This paper starts with the research question regarding the relationship between workplace conflicts and job satisfaction in the public sector in Serbia. Motivation: The main motivation for this research study was: to examine a compromising conflict resolution in the public sector in Serbia; to examine the frequency, causes, conflict resolution strategies and methods for their reduction and for improving work climate in the public sector in Serbia; to examine the job satisfaction in the public sector in Serbia; and to examine the relationship between workplace conflicts and job satisfaction in the public sector in Serbia. Idea: This research started with the intention to study job satisfaction or dissatisfaction and workplace conflicts in the public sector in Serbia in order to reach a more efficient and effective human resource management. Data: The research study was conducted from the beginning of March 2019 until the end of April 2019. The total sample size amounted to 300 respondents employed in the public sector in Serbia. Tools: Two scales have been used to gather data and conduct the research: the compromising conflict resolution scale and the job satisfaction survey scale. Findings: More than half of the respondents employed in the public sector in Serbia believe that conflicts in their workplace are not frequent, while less than half of them finds them frequent. This finding shows that opinions are divided regarding conflicts. As the main reason for conflicts, the respondents reported personal conflicts, organizational conflicts and communication conflicts. The best strategies to handle conflicts, according to the employees in the public sector in Serbia, are cooperation, competition and avoiding. At the same time, compromise occupies the bottom place according to its frequency occurrence. As regards the methods to lower the levels of conflict frequency and to improve the organizational climate, the employees in the public sector in Serbia emphasized better planning and division of work and more resources that a company has at its disposal. Regarding job satisfaction, these findings put employees in the category of ambivalent emotions. Contribution: The primary contribution of this paper is in its effort to lead to better human resource management in the public sector in Serbia due to the research study results.

Keywords: conflicts, job satisfaction, workplace, organization, public sector, Serbia

JEL Classification: C10, I31, M54

\section{Introduction}

Nowadays, one of the biggest challenges for most of organizations is low employee' engagement. Job satisfaction is one of the factors that increases employee engagement. Various studies have analyzed job satisfaction and identified factors at workplace that influence it. However, the relationship between conflicts and job satisfaction is still one of the widely analyzed and intriguing themes.

The purpose of this research paper is to examine the relationship between conflicts and job satisfaction in the public sector in Serbia. Job satisfaction and conflict management represent important aspects of human resource management (Stoner, Freeman \& Gilbert, 1995).1\} Some studies (De Dreu \& Van Vianen, 2001; Rahim, 2002) have identified that conflict management culture represents an important point in analyzing the 
workplace environment. Moreover, Choi and $\mathrm{Ha}$ (2008) have even discovered that it affects significantly a job satisfaction and productivity. Therefore, this research paper aims to examine the relationship between conflicts and job satisfaction in the public sector in Serbia. 1\}

The aim of the research is to:

1) study a compromising conflict resolution in the public sector in Serbia,

2) study the frequency, causes, conflict resolution strategies and methods for their reduction and for improving work climate in the public sector in Serbia,

3) study the job satisfaction in the public sector in Serbia, and

4) study the relationship between workplace conflicts and job satisfaction in the public sector in Serbia.

For the purpose of this research, we have proposed the following hypotheses:

$\mathrm{H} 1$ : There is a statistically significant difference between a compromising conflict resolution and sociodemographic characteristics of employees in the public sector in Serbia,

$\mathrm{H} 2$ : There is a statistically significant difference between the job satisfaction and socio-demographic characteristics of employees in the public sector in Serbia,

H3: There is a statistically significant correlation between a compromising conflict resolution and job satisfaction among employees in the public sector in Serbia,

$\mathrm{H} 4$ : There is statistically significant effect of gender on correlation between a compromising conflict resolution and job satisfaction in the public sector in Serbia,

H5: There is statistically significant effect of age on correlation between a compromising conflict resolution and job satisfaction in the public sector in Serbia.

The research study was conducted from the beginning of March 2019 until the end of April 2019. The total sample size included 300 respondents employed in the public sector in Serbia. The results show that more than a half of the respondents employed in the public sector in Serbia believe that conflicts in their workplace are not frequent, while less than a half of them finds them frequent. This finding shows that opinions regarding conflicts are divided. The main reasons for conflicts are personal conflicts, organizational conflicts and communication conflicts. Most frequently used to handle conflicts among the employees in the public sector are cooperation, competition and avoiding, while compromise occupies the bottom place according to its frequency occurrence. In order to lower the levels of conflict frequency and to improve the organizational climate, the employees in the public sector in Serbia emphasized a better planning and division of work and more resources that a company has at its disposal.

The paper consists of several sections. Firstly, we analyze the literature on the relevant concepts, such as workplace conflicts and job satisfaction. Secondly, we present the methodology and results. Finally, we elaborate on our results.

\section{Workplace Conflicts and Job Satisfaction in Organizations}

Workplace conflicts and job satisfaction are the two main factors that influence organizational efficiency. They have become crucial and have been studied in the last twenty years (Kian, Yusoff \& Rajah, 2014). Some studies even analyzed the moderating role of employees' collectivistic trait on the relationship between conflicts and employees' job satisfaction (Ye, Liu \& Gu, 2019).

\subsection{Workplace conflicts}

Workplace conflicts can be said to be one of the trending topics for researchers, both in psychology and in management (Williams, 2010). Different theories try to make their contributions in the study of human behavior, and to show how people achieve their personal growth and development in the workplace (Janicijevic, 2008).

Workplace conflicts and their resolution are the key questions for the entire human activity, personal value systems, work activities, as well as the society in which the process is going on. Both direct and indirect involvement in workplace conflicts have influence on individual well-being (Enehaug, Helmersen \& Mamelund, 2016). They are also one of the most intriguing and interesting subjects of the organizational behaviour and human resource management.

Workplace conflicts exist in the organizational structure and organizational culture in a specific way and they need to be resolved (Vujic, 2008). It is even believed that certain conflicts are wanted, especially those which are the product of life and work. This does not mean that conflicts should be created and encouraged, quite 
the opposite; harmful and destructive conflicts should be identified and resolved as soon as possible (Keranovic, 2005). Modern organizations use both constructive and destructive conflicts in order to achieve certain organizational goals, strengthen their cohesion, create positive organizational climate, and avoid disorganization (Jovanovic, Zivkovic \& Cvetkovski, 2007). More recent studies show that conflicts describe organizational real values and they suggested that organizational conflicts can be used as a tool to assess the implementation of organizational values (Titov, Virovere \& Kuimet, 2018).

Workplace conflict resolution depends on the type, character, extent and intensity of conflicts (Cvetkovski \& Cvetkovska-Ocokoljic, 2007). In workgroups conflicts frequently arise because people are highly interdependent and often share incompatible values (Carton \& Tewfik, 2016). Each type of conflicts demand an appropriate approach and method in order to be resolved. In this way positive and constructive effects of conflicts are reached, while destructive and negative effects are removed (Jovanovic, Kulic \& Cvetkovski, 2008). Whether the conflict is going to be resolved or only postponed so that it can reappear in new and changed circumstances, often even stronger, depends on the approach and conflict resolution strategy (Jovanovic, Zivkovic \& Cvetkovski, 2007).

According to Ting-Toomey's face negotiation theory, people from different cultures manage conflict differently (Ting-Toomey, 1988). Previous studies have discovered that members of collectivistic cultures are more oriented towards compromising styles of handling conflict whereas individualists prefer dominating (forcing) styles (Rahim, 1983; Ting-Toomey et al., 1991; Morris et al., 1998; Kozan \& Ergin, 1999; Holt \& DeVore, 2005; Wang, Jing \& Klossek, 2007; Gunkel, Schlaegel \& Taras, 2016; Caputo, Ayako \& Amoo, 2018). Since Serbia belongs to collectivistic cultures according to Hofstede's cultural dimensions (Hofstede, 2001), we believe that Serbian employees in the public sector will be oriented towards using a compromising conflict resolution.

The appropriate approach to conflict resolution is significant regarding the effectiveness and efficiency of the organization, and also regarding job satisfaction (Bojicic, Pavlovic \& Stojanovic-Visic, 2018).

\subsection{Job satisfaction}

Job satisfaction represents a measure, i.e., an estimation of emotions regarding the job or a cognitive estimation of the job (Judge \& Church, 2000). It is subjective and it represents an emotional feeling that people have regarding their jobs (Swarnalatha \& Tephillah, 2014). It also represents a complex attitude that involves certain presumptions and beliefs about the job, emotions and estimations about the job, and it has three main characteristics (Herzberg, 1966):

- Organizations should be guided by human values, and should treat their employees with respect, and in such circumstances job satisfaction can be an indicator of the efficiency of the employees,

- A high level of job satisfaction expresses a good emotional and mental health of the employees, which will affect the function and activities of the organization, and

- Job satisfaction is an indicator of the organizational activities.

In many theories and models of certain attitudes and behaviour, job satisfaction has an important part, and research into it can be applied to improve human lives and organizational efficiency (Judge \& Klinger, 2008). Hoboubi et al. (2017) examined the effects of job stress and job satisfaction on workforce productivity, and identified factors associated with productivity decrement among employees. Moreover, Saari and Judge (2004) concluded that the organization cannot influence the individual's personality, but if the employees choose jobs that suit them best, their job satisfaction will also increase. It is necessary for organizations to encourage their employees to stay and to do their jobs, but also to overcome work routine and turn to creativity and innovativeness (Pavlovic \& Markovic, 2014).

Even though there are certain differences in these definitions, job satisfaction is all about attitudes regarding the job, and it is viewed through two types of satisfactions based on the emotions about the job that employees have, namely, a general job satisfaction and emotions regarding certain workplace aspects, such as pay, benefits, hierarchy, promotions, work environment and the quality of the relationships with colleagues and management (Mueller \& Kim, 2008).

Based on different questionnaires that measure satisfaction with various job aspects, the following work dimensions have emerged (Spector, 1997): job, salary, promotion, the relationship with the superiors, relationship with the co-workers, benefits, rewards, work conditions, workplace safety, acquiring new knowledge, communication quality, and buyer satisfaction. 
Some research has shown that conflicts have negative effects on employees' job satisfaction. Kammerhoff et al. (2019) even showed that relationship conflict mediated the effect of transformational leadership on job satisfaction. De Wit et al. (2012) have also identified that conflicts had a negative effect on both job satisfaction and perceived organizational performance. On the other hand, some studies have concluded that conflicts can have both positive and negative effect on job satisfaction (Chen, Zhao, Liu \& Wu, 2012; De Dreu, 2006; Terason, 2018).

In the following part of the paper, we are going to provide the results of our study that analyzed the relationship between workplace conflicts and job satisfaction in the public sector in Serbia.

\section{Research Methodology}

The research study was conducted from the beginning of March 2019 until the end of April 2019. The respondents were given an already prepared questionnaire with a remark that the research is anonymous and that the received data will be used only for the purpose of this research study.

In order to collect data and do research two scales have been used: the compromising conflict resolution scale and the job satisfaction survey scale. In addition to these scales, the questionnaire also included three additional questions regarding the frequency, main causes and best strategies for resolving workplace conflicts between the employees in the public sector, as well as the question about the methods which would improve the company's climate and reduce conflicts. Furthermore, there is also a part in the questionnaire that is related to general socio-demographic characteristics of the respondents (gender and age).

\subsection{Research sample}

The total research sample size amounts to 300 respondents, employed in the public sector in Serbia. The research sample has been viewed through general socio-demographic characteristics (gender and age).

Regarding the gender of the respondents, a little more than a half of the sample are female respondents $(59.8 \%)$, and a little less than a half are male respondents $(40.2 \%)$. It can be said that the sample is balanced according to gender.

Regarding the age of the respondents, most employees in the public sector are 31 to 40 years old (45.1\%). The youngest respondents, aged 18 to 30 , are at the second place (22.5\%), and the respondents from 41 to 50 years of age are at the third place (13.7\%). There are significantly fewer employees in the public sector who are 51 to 60 years old (12.7\%) or 61 and older $(5.9 \%)$.

\subsection{Reliability of the research instruments}

In order to collect data and do the research, two scales have been used: the compromising conflict resolution scale and the job satisfaction survey scale.

The compromising conflict resolution scale (CCR scale) was constructed for this research. The scale has closed-ended questions and it contains 18 statements for rating on a scale 1 to 5 (Likert scale). Replies are classified from 1 - never, to 5 - always, and a higher score on this scale means a higher level of readiness to express a compromising behavior while resolving workplace conflicts. Statements 1,6 and 9 are inverted and are reverse scored ( 1 - always, 5 - never). The scope of scores on the scale is from the minimum of 18 to the maximum 90 .

The job satisfaction survey scale (JSS scale) was designed by Spector (1997). The scale is a questionnaire for measuring job satisfaction on a six-point scale from 1 - strongly disagree to 6 - strongly agree. The statements 2, 4, 6, 8, 10, 12, 14, 16, 18, 19, 21, 23, 24, 26, 29, 31, 32, 34 and 36 are inverted and are reversely scored. The scale contains 36 items and based on the data received through this scale we can get ten independent scores. Nine scores are the results of the individual subscales, and the tenth score is the summative score of the respondents for all items and it represents the general measurement of the job satisfaction. Nine facets of the job satisfaction measured by this scale are: pay, promotion, supervision, benefits, contingent rewards, operating procedures, co-workers, nature of work and communication. The range of the entire JSS scale is from 36 to 216, where the range from 36 to 108 signifies dissatisfaction, 
from 108 to 144 ambivalence, and from 144 to 216 job satisfaction. For individual aspects or subscales, the range is from 4 to 24 , where scores from 4 to 12 mean dissatisfaction, from 12 to 16 ambivalence, and from 16 to 24 job satisfaction.

Regarding the reliability of the instruments, both scales have acceptable reliability (above arbitrary level $\alpha<0.70$ ). Reliability for CCR scale is $\alpha=0.850$ and it is considered high (above $\alpha<0.80$ ), while for JSS scale it is $\alpha=0.740$. Both alpha coefficients show the reliability of the scales, especially considering the fact that the CCR scale has only 18 statements, and JSS scale has 36 statements.

\section{Research Results}

Based on the gathered data, with the use of the CCR scale and the JSS scale, the following issues have been studied: a compromising conflict resolution; the frequency, causes, conflict resolution strategies and methods for their reduction and for improving work climate; the job satisfaction; and the relationship between workplace conflicts and job satisfaction.

\subsection{The study of a compromising conflict resolution in the public sector in Serbia}

The compromising conflict resolution scale (CCR scale), on the level of the entire sample size, shows an above average value $(A S=55.88, S D=7.656)$. The empirical minimum is 39 , and maximum is 73 . Regarding the range of the scale (18 to 90 ), the received score is considered high, or even above average.

The levels of compromising conflict resolution were also studied in relation to socio-demographic characteristics of the respondents: gender and age. Regarding the gender of the respondents, there were no statistically significant differences of scores on the CCR scale $(t=-0.205, p=0.838)$. Somewhat higher value was received with the male respondents $(A S=56.07, S D=6.890)$, and lower with female respondents $(A S=55.75, S D=8.185)$.

Regarding the age of the respondents, there were no statistically significant differences in the levels of compromising conflict resolution $(F=0.492, p=0.742)$. The highest score was received with the youngest respondents, aged 18 to 30 ( $A S=57.52, S D=7.360$ ), and the lowest score was gained with the oldest respondents who are 61 and older $(A S=54.50, S D=11.640)$.

Regarding the scores for certain items of the CCR scale, the highest score was received for statement 7: While resolving conflicts, I try to do it to the mutual satisfaction ( $\mathrm{AS}=3.93, \mathrm{SD}=0.870$ ) and statement 13: When I am in conflict with other co-workers, I always ask them to explain to me what the problem is $(\mathrm{AS}=3.86$, $\mathrm{SD}=0.890$ ). The highest score was also received for statement 14: It is not a problem for me to accept the criticism of others $(\mathrm{AS}=3.75, \mathrm{SD}=0.829)$ and statement 11 : I negotiate with my co-workers in order to find a compromising solution ( $\mathrm{AS}=3.70, \mathrm{SD}=0.888$ ). The lowest score was for statement 1 : When somebody does not agree with me, I defend my opinion $(A S=2.04, S D=1.024)$ and statement 6 : While resolving a conflict, I try to maintain my opinion ( $\mathrm{AS}=2.12, \mathrm{SD}=0.937)$.

4.2. The study of the frequency, causes, conflict resolution strategies and methods for their reduction and for improving work climate in the public sector in Serbia

This questionnaire, in addition to the CCR scale, also has three additional questions relating to the frequency, main causes and best strategies for conflict resolution in the public sector, and also relating to the methods in order to improve work climate and reduce the frequency of conflicts.

The opinion was divided among the public sector employees as to whether there are frequent conflicts in their workplace. $49.0 \%$ of the employees believe that conflicts are frequent, while $51.0 \%$ believe they are not frequent.

As the main cause for workplace conflicts the respondents indicated personal reasons (38.2\%). Organizational conflicts are at the second place (36.3\%), and communication conflicts at the third (25.5\%). It may be said that, as in the relation to the frequency of conflicts, the opinion of the employees in the public sector is divided and that all three causes of conflicts are present more or less equally. 
The best strategy for conflict resolution, the respondents stated, was cooperation (34.3\%). Besides this, at the second place according to its frequency is competition $(22.5 \%)$, and avoidance is at the third place (21.6\%). Furthermore, $12.7 \%$ of the employees in the public sector chose reconciliation as a strategy for conflict resolution, and only $8.8 \%$ chose compromise.

Regarding the methods for improving work climate and for reducing the frequency of conflicts, most employees in the public sector chose better planning and division of work (almost two thirds of the sample, or $67.6 \%)$, then more resources that a company has at its disposal (47.1\%), more care for the employees $(40.2 \%)$, as well as a more qualitative supervision at all levels (31.4\%). The least frequency was given to a better rewarding system (22.5\%) and better communication (24.5\%).

\subsection{The study of the job satisfaction in the public sector in Serbia}

The job satisfaction survey scale (JSS scale), as has already been mentioned, consists of 36 statements and has theory range from 36 to 216 . The range of scores from 36 to 108 means dissatisfaction, from 108 to 144 ambivalence, and from 144 to 216 job satisfaction. For certain aspects or subscales, the theory range is from 4 to 24, where scores from 4 to 12 mean dissatisfaction, from 12 to 16 ambivalence, and from 16 to 24 job satisfaction.

Across the total sample, regarding the general job satisfaction (JSS Sum), the received value is AS $=125.75$, $\mathrm{SD}=12.319$. The empirical minimum is 90 , and maximum is 150 . This result puts employees in the category of ambivalence (neither satisfied nor dissatisfied). The similar results were also received regarding the scores on certain dimensions of the JSS scale. In fact, the highest score was received for dimension Operating procedures $-A S=16.21, S D=3.170$. The score for this dimension is at the same time the only one in the category of job satisfaction (or on the border between ambivalence and satisfaction). The received scores on other dimensions are in the category of ambivalence, and only the dimension Promotion received the score that shows dissatisfaction $(<12)-A S=10.66, S D=3.007$. Moreover, the dimensions Co-workers $(A S=15.73, S D=2.611)$, Supervision $(A S=15.57, S D=1.875)$, Communication $(A S=15.41, S D=2.653)$ and Contingent rewards $A S=15.10, S D=3.170)$ received scores that are closer to job satisfaction. For dimensions Nature of work, Pay and Benefits the received scores are between ambivalence and dissatisfaction.

Regarding the gender of the respondents, there are no statistically significant differences in the scores on the JSS scale, nor in its dimensions. The biggest difference based on F statistics has been received for the dimension Co-workers $(F=1.859, p=0.066)$ which may be said to be on the border of statistical significance (but is not significant) with $p<0.05$.

Regarding the scores in relation to the gender of the respondents, on the total score of JSS Sum and dimensions Pay, Supervision, Contingent rewards, Operating procedures and Co-workers higher scores were received with female respondents, while with male respondents offered higher scores for dimensions Promotion, Benefits, Nature of work and Communication.

Regarding the age of the respondents, a statistically significant difference was received for the dimension Co-workers $(F=3.466, p=0.011)$. The received difference is significant at the level $p<0.05$ and further analysis (LSD) showed that employees in the public sector aged 41 to $50(A S=16.86, S D=2.905)$ and 51 to 60 $(A S=17.38, S D=2.142)$ have significantly higher scores at this dimension than employees aged 18 to 30 $(A S=15.17, S D=2.387)$, and those aged 31 to $40(A S=15.07, S D=2.426)$.

In addition, it is necessary to say that on the total score of the JSS scale the highest score was received with the oldest respondents, aged 61 and older $(A S=132.17, S D=13.761)$, and the lowest with the youngest respondents, aged 18 to 30 ( $\mathrm{AS}=122.83, \mathrm{SD}=9.476)$.

\subsection{The study of the relationship between workplace conflicts and job satisfaction in} the public sector in Serbia

Based on the general idea of this research paper, the aim was to study the relationship between the levels of compromising conflict resolution in the workplace and job satisfaction of the employees in the public sector. The research results showed that the level of the CCR scale is statistically significantly related to the summation score of the JSS scale $(r=-0.272, p=0.006)$, and also with the dimensions Contingent rewards $(r=-0.211, p=0.033)$, Nature of work $r=-0.265, p=0.007)$ and Communication $r=-0.247, p=0.012)$. The correlation of the CCR scale and the summation score (JSS Sum) and dimension Nature of work is significant 
at level $p<0.01$ and in relation to dimensions Contingent rewards and Communication at level $p<0.05$. All these correlations are negative and they show that with the increase of the level of job satisfaction, the level of compromising conflict resolution in the workplace decreases.

In addition to the correlations between a compromising conflict resolution and job satisfaction, the JSS Sum has also shown numerous correlations between all nine dimensions. All received correlations are positive and significant at level $p<0.01$. The only exception is correlation in relation to the dimension Supervision which is significant at level $p<0.05$ (on the border between $p<0.01$ and $p<0.05$ ). These positive correlations show that with the increase of scores on the summation score of the JSS scale, the scores on its dimensions also increase, and vice versa.

This finding has been expected, as well as the received correlation within the dimensions of the JSS scale. It is interesting that the dimensions Nature of work and Operating procedures $(r=-0.209, p=0.035)$ have negative correlations, while all other correlations within the dimensions of the JSS scale are positive.

After a detailed insight into the correlation between levels of compromising conflict resolution and job satisfaction, the correlation of these two scales (CCR scale and JSS scale) was conducted in relation to the gender and age of the respondents (Table $1 \&$ Table 2).

Table 1: Correlation between levels of compromising conflict resolution and job satisfaction in relation to the gender of the respondents

\begin{tabular}{|c|c|c|c|}
\hline \multirow{2}{*}{\multicolumn{2}{|c|}{ Correlation }} & \multicolumn{2}{|c|}{ CCR } \\
\hline & & female $^{1}$ & male $^{2}$ \\
\hline JSS Sum & $\begin{array}{l}\mathbf{r} \\
\mathbf{p} \\
\mathbf{N}\end{array}$ & $\begin{array}{c}-0.317 \\
0.013^{\star} \\
179\end{array}$ & $\begin{array}{c}-0.195 \\
0.223 \\
121 \\
\end{array}$ \\
\hline Pay & $\begin{array}{l}\mathbf{r} \\
\mathbf{p} \\
\mathbf{N}\end{array}$ & $\begin{array}{c}-0.151 \\
0.246 \\
179 \\
\end{array}$ & $\begin{array}{c}0.038 \\
0.814 \\
121 \\
\end{array}$ \\
\hline Promotion & $\begin{array}{l}\mathbf{r} \\
\mathbf{p} \\
\mathbf{N}\end{array}$ & $\begin{array}{c}-0.078 \\
0.551 \\
179 \\
\end{array}$ & $\begin{array}{c}-0.111 \\
0.488 \\
121 \\
\end{array}$ \\
\hline Supervision & $\begin{array}{l}\mathbf{r} \\
\mathbf{p} \\
\mathrm{N}\end{array}$ & $\begin{array}{c}0.084 \\
0.521 \\
179 \\
\end{array}$ & $\begin{array}{c}0.119 \\
0.460 \\
121 \\
\end{array}$ \\
\hline Benefits & $\begin{array}{l}\mathbf{r} \\
\mathbf{p} \\
\mathrm{N}\end{array}$ & $\begin{array}{c}-0.175 \\
0.178 \\
179\end{array}$ & $\begin{array}{c}-0.233 \\
0.143 \\
41\end{array}$ \\
\hline Contingent rewards & $\begin{array}{l}\mathbf{r} \\
\mathbf{p} \\
\mathrm{N}\end{array}$ & $\begin{array}{c}-0.257 \\
0.045^{\star} \\
179\end{array}$ & $\begin{array}{c}-0.142 \\
0.377 \\
121\end{array}$ \\
\hline Operating procedures & $\begin{array}{l}\mathbf{r} \\
\mathbf{p} \\
\mathbf{N}\end{array}$ & $\begin{array}{c}-0.205 \\
0.113 \\
179\end{array}$ & $\begin{array}{c}0.032 \\
0.840 \\
121 \\
\end{array}$ \\
\hline Co-workers & $\begin{array}{l}\mathbf{r} \\
\mathbf{p} \\
\mathbf{N}\end{array}$ & $\begin{array}{c}-0.265 \\
0.039 * \\
179\end{array}$ & $\begin{array}{c}0.098 \\
0.542 \\
121 \\
\end{array}$ \\
\hline Nature of work & $\begin{array}{l}\mathbf{r} \\
\mathbf{p} \\
\mathbf{N}\end{array}$ & $\begin{array}{c}-0.312 \\
0.014^{\star} \\
179\end{array}$ & $\begin{array}{c}-0.167 \\
0.296 \\
121 \\
\end{array}$ \\
\hline Communication & $\begin{array}{l}\mathbf{r} \\
\mathbf{p} \\
\mathbf{N}\end{array}$ & $\begin{array}{c}-0.078 \\
0.551 \\
179 \\
\end{array}$ & $\begin{array}{c}-0.532 \\
0.000 * * \\
121\end{array}$ \\
\hline
\end{tabular}

$d f 1=179 ; d f 2=121 ; p<0.01^{* *} ; p<0.05^{*}$;

The obtained findings showed that in the subsample of female respondents (Table 1), the correlation of the level of compromising conflict resolution is in relation to JSS Sum $(r=-0.317, p=0.013)$ and in relation to the dimensions Contingent rewards $(r=-0.257, p=0.045)$, Co-workers $(r=-0.265, p=0.039)$ and Nature of work $(r=-0.312, p=0.014)$. The obtained correlations in the subsample of female respondents are significant at the level of significance of $p<0.05$ and have a negative sign, which indicates that with the increasing level of compromising conflict resolution, the level of job satisfaction decreases. In the subsample of male 
respondents, statistically significant correlation between levels of compromising conflict resolution and job satisfaction was obtained only for the dimension Communication $(r=-0.532, p=0.000)$. The obtained correlation is significant at the level of $p<0.01$ and also has a negative sign.

Table 2: Correlation between levels of compromising conflict resolution and job satisfaction in relation to the age of the respondents

\begin{tabular}{|c|c|c|c|c|c|c|}
\hline \multirow{2}{*}{\multicolumn{2}{|c|}{ Correlation }} & \multicolumn{5}{|c|}{ CCR } \\
\hline & & $18-30^{1}$ & $31-40^{2}$ & $41-50^{3}$ & $51-60^{4}$ & 61 and older 5 \\
\hline JSS Sum & $\begin{array}{l}r \\
p \\
N\end{array}$ & $\begin{array}{c}0.037 \\
0.866 \\
68\end{array}$ & $\begin{array}{c}-0.193 \\
0.199 \\
135\end{array}$ & $\begin{array}{c}-0.286 \\
0.322 \\
41\end{array}$ & $\begin{array}{c}-0.530 \\
0.062 \\
38\end{array}$ & $\begin{array}{c}-0.682 \\
0.135 \\
18\end{array}$ \\
\hline Pay & $\begin{array}{l}r \\
p \\
N\end{array}$ & $\begin{array}{c}0.370 \\
0.082 \\
68\end{array}$ & $\begin{array}{c}-0.081 \\
0.593 \\
135\end{array}$ & $\begin{array}{c}0.124 \\
0.673 \\
41\end{array}$ & $\begin{array}{c}-0.410 \\
0.165 \\
38\end{array}$ & $\begin{array}{c}-0.893 \\
0.017^{\star} \\
18\end{array}$ \\
\hline Promotion & $\begin{array}{l}r \\
p \\
N\end{array}$ & $\begin{array}{c}-0.234 \\
0.282 \\
68\end{array}$ & $\begin{array}{c}0.019 \\
0.899 \\
135\end{array}$ & $\begin{array}{c}-0.304 \\
0.291 \\
41\end{array}$ & $\begin{array}{c}-0.178 \\
0.561 \\
38\end{array}$ & $\begin{array}{c}0.449 \\
0.371 \\
18\end{array}$ \\
\hline Supervision & $\begin{array}{l}r \\
p \\
N\end{array}$ & $\begin{array}{c}0.146 \\
0.506 \\
68 \\
\end{array}$ & $\begin{array}{c}0.108 \\
0.476 \\
135 \\
\end{array}$ & $\begin{array}{c}-0.105 \\
0.721 \\
41\end{array}$ & $\begin{array}{c}-0.178 \\
0.560 \\
38\end{array}$ & $\begin{array}{c}0.729 \\
0.100 \\
18\end{array}$ \\
\hline Benefits & $\begin{array}{l}r \\
p \\
N\end{array}$ & $\begin{array}{c}-0.257 \\
0.237 \\
68\end{array}$ & $\begin{array}{c}0.027 \\
0.858 \\
135\end{array}$ & $\begin{array}{c}-0.502 \\
0.068 \\
41\end{array}$ & $\begin{array}{c}-0.266 \\
0.380 \\
38\end{array}$ & $\begin{array}{c}-0.470 \\
0.347 \\
18\end{array}$ \\
\hline Contingent rewards & $\begin{array}{l}\mathbf{r} \\
\mathbf{p} \\
\mathrm{N}\end{array}$ & $\begin{array}{c}-0.108 \\
0.625 \\
68 \\
\end{array}$ & $\begin{array}{c}-0.190 \\
0.205 \\
135\end{array}$ & $\begin{array}{c}-0.030 \\
0.919 \\
41\end{array}$ & $\begin{array}{c}-0.243 \\
0.424 \\
38\end{array}$ & $\begin{array}{c}-0.649 \\
0.163 \\
18\end{array}$ \\
\hline Operating procedures & $\begin{array}{l}\mathbf{r} \\
\mathbf{p} \\
\mathrm{N}\end{array}$ & $\begin{array}{c}0.174 \\
0.427 \\
68 \\
\end{array}$ & $\begin{array}{c}-0.136 \\
0.368 \\
135\end{array}$ & $\begin{array}{c}-0.131 \\
0.654 \\
41\end{array}$ & $\begin{array}{c}-0.286 \\
0.343 \\
38\end{array}$ & $\begin{array}{c}-0.358 \\
0.486 \\
18 \\
\end{array}$ \\
\hline Co-workers & $\begin{array}{l}\mathbf{r} \\
\mathbf{p} \\
\mathrm{N}\end{array}$ & $\begin{array}{c}0.129 \\
0.557 \\
68\end{array}$ & $\begin{array}{c}-0.201 \\
0.180 \\
135\end{array}$ & $\begin{array}{c}0.084 \\
0.775 \\
41\end{array}$ & $\begin{array}{c}-0.394 \\
0.183 \\
38\end{array}$ & $\begin{array}{c}-0.821 \\
0.04{ }^{\star} \\
18\end{array}$ \\
\hline Nature of work & $\begin{array}{l}\mathbf{r} \\
\mathbf{p} \\
\mathrm{N}\end{array}$ & $\begin{array}{c}-0.089 \\
0.687 \\
68\end{array}$ & $\begin{array}{c}-0.336 \\
0.022 * \\
135\end{array}$ & $\begin{array}{c}-0.109 \\
0.711 \\
41\end{array}$ & $\begin{array}{c}-0.746 \\
0.003^{\star *} \\
38\end{array}$ & $\begin{array}{c}-0.346 \\
0.502 \\
18\end{array}$ \\
\hline Communication & $\begin{array}{l}\mathbf{r} \\
\mathrm{p} \\
\mathrm{N}\end{array}$ & $\begin{array}{c}-0.004 \\
0.985 \\
68\end{array}$ & $\begin{array}{c}-0.152 \\
0.312 \\
135\end{array}$ & $\begin{array}{c}-0.383 \\
0.176 \\
41\end{array}$ & $\begin{array}{c}-0.443 \\
0.129 \\
38\end{array}$ & $\begin{array}{c}-0.594 \\
0.214 \\
18\end{array}$ \\
\hline
\end{tabular}

$d f 1=68 ; d f 2=135 ; d f 3=41 ; d f 4=38 ; d f 5=38 ; p<0.01 * * ; p<0.05^{*}$;

When it comes to the age of the respondents (Table 2), in the subsamples of respondents aged 18 to 30 years and 41 to 50 years, no correlation was obtained between levels of compromising conflict resolution and job satisfaction. In the subsample of respondents aged 31 to 40 years, a statistically significant correlation of the level of compromising conflict resolution was confirmed in relation to the dimension Nature of work $(r=-0.336, p=0.022)$. In addition, the same correlation, compromising conflict resolution was confirmed in relation to the dimension Nature of work, in the subsample of the respondents aged 51 to 60 years $(r=-0.746, p=0.003)$, while in a subsample of the respondents aged 61 and over, there was a statistically significant correlation between levels of compromising conflict resolution and job satisfaction in relation to the dimensions Pay $(r=-0.893, p=0.017)$ and Co-workers $(r=-0.821, p=0.045)$. All obtained correlations were significant at the significance level of $p<0.05$, except for the correlation obtained in a subsample of the respondents aged 51 to 60 years, which is significant at the significance level of $p<0.01$. Furthermore, all the obtained correlations have a negative sign, which indicates that with the increase in the expression of job satisfaction, the level of compromising conflict resolution decreases and vice versa.

\section{Discussion}

Our results give the support to $\mathrm{H} 3$, while $\mathrm{H} 2, \mathrm{H} 4$ and $\mathrm{H} 5$ are partially supported, and $\mathrm{H} 1$ is not supported.

The scores on the CCR scale show that there is an above average value which shows the readiness of the respondents to reach a compromising conflict resolution. These statements have the highest value: While 
resolving a conflict I try to do it to the mutual satisfaction, and When I am in conflict with other co-workers, I always ask them to explain to me what the problem is, while the lowest value is for the statements: When somebody does not agree with me, I defend my opinion, and While resolving a conflict, I try to maintain my opinion. Our study supports the assumption that people from collectivistic cultures are less willing to use forcing styles of conflict management (e.g., Kagan, Knight \& Martinez-Romero, 1982; Leung, 1988; Chiu \& Kosinski, 1994; Elsayed-EkJiouly \& Buda, 1996; Holt \& DeVore, 2005; Boonsathorn, 2007; Gunkel, Schlaegel \& Taras, 2016).

The received values according to the JSS scale categorize employees as ambivalent (neither satisfied nor dissatisfied). Similar results were also received for some other dimensions. In fact, the highest score was reached for the dimension Operating procedures. The score for this dimension is at the same time the only one in the job satisfaction category. The received scores for other dimensions are in the category of ambivalence, and only the score for the dimension Promotion shows dissatisfaction. It is necessary to emphasize that received scores for the dimensions Co-workers, Supervision, Communication and Contingent rewards are closer to ambivalence than to job satisfaction, while scores for the dimensions Nature of work, Pay and Benefits are between ambivalence and dissatisfaction.

Regarding $\mathrm{H} 1$ (There is a statistically significant difference between a compromising conflict resolution and socio-demographic characteristics of employees in the public sector in Serbia), the findings reveal that there is no statistically significant difference between a compromising conflict resolution and socio-demographic characteristics. However, $\mathrm{H} 2$ (There is a statistically significant difference between the job satisfaction and socio-demographic characteristics of employees in the public sector in Serbia) is partially confirmed, i.e., there is a statistically significant difference between some socio-demographic characteristics, but not between all. On the JSS scale, statistically significant differences are received concerning the age of the respondents.

In addition to the study of a compromising conflict resolution and the levels of job satisfaction of the total sample, the research also included the study of these scores according to socio-demographic characteristics of the respondents - gender and age. The research results showed that there are no statistically significant differences on the CCR scale in relation to socio-demographic characteristics of the respondents, and on the JSS scale statistically significant differences were revealed in relation to the age of the respondents. Regarding the age of the respondents, the dimension Co-workers was statistically significant on the JSS scale, and further analysis showed that for this dimension employees in the public sector in Serbia aged 41 to 50 , and 51 to 60 have significantly higher scores than the employees who are 18 to 30 years old and those aged 31 to 40 .

Moreover, this research also included the relationship between compromising conflict resolution in the workplace and levels of job satisfaction of the employees in the public sector in Serbia. The results confirm H3 (There is a statistically significant correlation between a compromising conflict resolution and job satisfaction among employees in the public sector in Serbia) since there is the correlation between a compromising conflict resolution and job satisfaction. Based on the received data there is a correlation between the CCR scale, the summation score - JSS Sum and the dimensions Contingent rewards, Nature of work and Communication. All these correlations are negative and show that with the increase of the level of job satisfaction, the level of compromising conflict resolution in the workplace decreases. This finding can be interpreted in many ways, and it may be assumed that compromising conflict resolution demand a lot of mental energy, and people often interpret such an effort as job dissatisfaction. On the whole, the more a person invests in compromising conflict resolution, the less satisfied they are with their job.

When it comes to correlations between CCR scale and JSS scale in relation to the gender of the respondents, the research results show that in the subsample of female respondents there is a correlation of compromising conflict resolution in relation to the average of the entire scale of job satisfaction and with the dimensions Contingent rewards, Co-workers and Nature of work. In the subsample of male respondents, a statistically significant correlation between the level of compromising conflict resolution and job satisfaction was obtained only for the dimension Communication. These results partially confirm H4 (There is statistically significant effect of gender on correlation between a compromising conflict resolution and job satisfaction in the public sector in Serbia). In addition, it is important to mention that all obtained correlations, both in the subsample of female respondents and in the subsample of male respondents, had a negative sign, which indicates that with the increasing level of compromising conflict resolution, the degree of job satisfaction decreases.

Similarly, in addition to examining the correlations between CCR scale and JSS scale according to the gender of the respondents, the research also examined the correlation between CCR scale and JSS scale according to the age categories of the respondents. The obtained findings showed that statistically significant correlations exist in the subsamples of respondents aged 31 to 40 years, from 51 to 60 years and in the subsample of 
respondents aged 61 and over. These results partially confirm H5 (There is statistically significant effect of age on correlation between a compromising conflict resolution and job satisfaction in the public sector in Serbia). Moreover, it is important to mention that the obtained results showed that in the subsamples of respondents aged 31 to 40 years, and 51 to 60 years, statistically significant correlations of the level of compromising conflict resolution exist in relation to the dimension Nature of work. In the subsample of respondents aged 61 and over, a statistically significant correlation between levels of compromising conflict resolution and job satisfaction was confirmed in relation to the dimensions Pay and Co-workers. Also, it is important to note that all the obtained correlations have a negative direction, which indicates that with the increase in the level of compromising conflict resolution, the degree of the expression of job satisfaction decreases.

\section{Conclusion}

The aim of this paper is to study the level of conflicts and the level of job satisfaction among the employees in the public sector in Serbia. In order to collect data, two scales have been used: the compromising conflict resolution scale (CCR scale), specially created for the purposes of this research, and the job satisfaction survey scale (JSS scale).

We believed that the main cause of conflict in the public sector in Serbia was related to tasks. However, the results show that employees mainly argue due to relational issues, e.g., aversion among employees, hostility, creating obstacles against one another, etc. Moreover, regarding conflicts in the workplace, a little more than a half of the employees in the public sector in Serbia believe that conflicts are not frequent, and a little less than a half of them believe they are frequent. This finding shows that opinions about conflicts are divided. As the main cause of conflicts, the respondents point out personal conflicts, organizational conflicts and communication conflicts. The best strategies to handle conflicts, according to most employees in the public sector in Serbia are cooperation, competition, and then avoidance, while compromise is at the lower position place. Regarding the methods for reducing the frequency of conflicts and for improving work climate, employees in the public sector in Serbia prefer better planning and division of work and more resources that a company has at its disposal.

\section{REFERENCES}

[1] Bojicic, R., Pavlovic, M. \& Stojanovic-Visic B. (2018). Zadovoljstvo poslom u EU, Rusiji i Srbiji komparativna analiza. Vojno delo, 70(7), 354-369. DOI: 10.5937/vojdelo1807354B

[2] Boonsathorn, W. (2007). Understanding conflict management styles of Thais and Americans in multinational corporations in Thailand. International Journal of Conflict Management, 18(3), 196-221. DOI: $10.1108 / 10444060710825972$

[3] Caputo, A., Ayako, O. B. \& Amoo, N. (2018). The moderating role of cultural intelligence in the relationship between cultural orientations and conflict management styles. Journal of Business Research, 89, 10-20. DOI: 10.1016/j.jbusres.2018.03.042

[4] Carton, A. M. \& Tewfik, B. A. (2016). Perspective-A new look at conflict management in work groups. Organization Science, 27(5), 1125-1141. DOI: 10.1287/orsc.2016.1085

[5] Chen, X. H., Zhao, K., Liu, X. \& Wu, D. D. (2012). Improving employees' job satisfaction and innovation performance using conflict management. International Journal of Conflict Management, 23(2), 151-172. DOI: $10.1108 / 10444061211218276$

[6] Chiu, R. K. \& Kosinski, F. A. (1994). Is Chinese conflict handling behavior influenced by Chinese values?. Social Behavior and Personality: an international journal, 22(1), 81-90. DOI: 10.2224/sbp.1994.22.1.81

[7] Choi, Y. \& Ha, J. (2018). Job satisfaction and work productivity: The role of conflict-management culture. Social Behavior and Personality: an international journal, 46(7), 1101-1110. DOI: 10.2224/sbp.6940

[8] Cvetkovski T. \& Cvetkovska-Ocokoljic, V. (2007). Poslovna komunikacija u savremenim uslovima poslovanja. Megatrend univerzitet, Beograd.

[9] De Dreu, C. K. W. (2006). When too little or too much hurts: Evidence for a curvilinear relation between task conflict and innovation in teams. Journal of Management, 32(1), 83-107. DOI: 10.1177/0149206305277795

[10] De Dreu, C. K. W. \& Van Vianen, A. E. M. (2001). Managing relationship conflict and the effectiveness of organizational teams. Journal of Organizational Behavior, 22(3), 309-328. DOI:

[11] De Wit, F. R. C., Greer, L. L. \& Jehn, K. A. (2012). The paradox of intragroup conflict: A meta-analysis. Journal of Applied Psychology, 97(2), 360-390. DOI: 10.1037/a0024844

[12] Elsayed-EkJiouly, S. M. \& Buda, R. (1996). Organizational conflict: a comparative analysis of conflict across cultures. International Journal of Conflict Management, 7(1), 71-81. DOI: 10.1108/eb022776 
[13] Enehaug, H., Helmersen, M. \& Mamelund, S.-E. (2016). Individual and Organizational Well-being when Workplace Conflicts are on the Agenda: A Mixed-methods Study. Nordic Journal of Working Life Studies, 6(1), 83-104. DOI: 10.19154/njwls.v6i1.4911

[14] Gunkel, M., Schlaegel, C. \& Taras, V. (2016). Cultural values, emotional intelligence, and conflict handling styles: A global study. Journal of World Business, 51(4), 568-585. DOI: 10.1016/j.jwb.2016.02.001

[15] Herzberg, F. (1966). Work and the nature of man. Cleveland, OH: World Publishing Co.

[16] Hoboubi, N., Choobineh, A., Ghanavati, F. K., Keshavarzi, S. \& Hosseini, A. A. (2017). The impact of job stress and job satisfaction on workforce productivity in an Iranian petrochemical industry. Safety and health at work, 8(1), 67-71. DOI: 10.1016/j.shaw.2016.07.002

[17] Hofstede, G. (2001). Culture's recent consequences: Using dimensions scores in theory and research. International Journal of cross cultural management, 1(1), 11-17. DOI: 10.1177/147059580111002

[18] Holt, J. L. \& DeVore, C. J. (2005). Culture, gender, organizational role, and styles of conflict resolution: A meta-analysis. International Journal of Intercultural Relations, 29(2), 165-196. DOI: 10.1016/j.jijintrel.2005.06.002

[19] Janicijevic, N. (2008). Organizaciono ponašanje. Data status, Beograd.

[20] Jovanovic, M., Kulic, Z. \& Cvetkovski T. (2008). Osnovi upravljanja ljudskim resursima. Megatrend univerzitet, Beograd.

[21] Jovanovic, M., Zivkovic, M. \& Cvetkovski T. (2007). Organizaciono ponašanje. Megatrend univerzitet primenjenih nauka, Beograd.

[22] Judge, T. A. \& Church, A. H. (2000). Job satisfaction: Research and practice. In: C. L. Cooper \& E. A. Locke (Eds.), Industrial and Organizational Psychology: Linking Theory With Practice (pp. 166-198). Oxford, UK: Blackwell.

[23] Judge, T. A. \& Klinger, R. (2008). Job satisfaction: Subjective well-being at work. In: M. Eid \& R. Larsen (Eds.), The Science of Subjective Well-Being (pp. 393-413). Guilford Publications, New York.

[24] Kagan, S., Knight, G. \& Martinez-Romero, S. (1982). Culture and the development of conflict resolution style. Journal of Cross-Cultural Psychology, 13(1), 43-58. DOI: 10.1177/0022022182131005

[25] Kammerhoff, J., Lauenstein, O. \& Schütz, A. (2019). Leading toward harmony—Different types of conflict mediate how followers' perceptions of transformational leadership are related to job satisfaction and performance. European Management Journal, 37(2), 210-221. DOI: 10.1016/j.emj.2018.06.003

[26] Keranovic, S. (2005). Sociologija rada. Viša škola za informacione i komunikacione tehnologije, Beograd.

[27] Kian, T. S., Yusoff W. \& Rajah S. (2014). Job satisfaction and motivation: what are the difference among these two? European Journal of Business and Social Sciences, 3(2), 94-102.

[28] Kozan, M. K. \& Ergin, C. (1999). The influence of intra-cultural value differences on conflict management practices. International Journal of Conflict Management, 10(3), 249-267. DOI: 10.1108/eb022826

[29] Leung, K. (1988). Some determinants of conflict avoidance. Journal of Cross Cultural Psychology, 19(1), 125-136. DOI: 10.1177/0022002188019001009

[30] Morris, M. W., Williams, K. Y., Leung, K., Larrick R., Mendoza M. T., Bhatnagar D., Li J., Kondo M., Luo J.-L. \& Hu J.-C. (1998). Conflict management style: accounting for cross-national differences. Journal of International Business Studies, 29, 729-747. DOI: 10.1057/palgrave.jibs.8490050

[31] Mueller, C. W. \& Kim, S.-W. (2008). The contented female worker: Still a paradox?. In: K. A. Hegtvedt \& J. Clay-Warner (Eds.), Justice: Advances in group processes, 25 (pp.117-149). Bingley, UK: Emerald Group Publishing Limited. DOI: 10.1016/S0882-6145(08)25006-X

[32] Pavlovic, M. \& Markovic, D. (2014). Teorijski pristup zadovoljstvu poslom i motivaciji zaposlenih. Vojno delo, 66(1), 289-302. DOI: 10.5937/vojdelo1401289P

[33] Rahim, M. A. (1983). A measure of styles of handling interpersonal conflict. The Academy of Management Journal, 26(2), 368-376. DOI: 10.5465/255985

[34] Rahim, M. A. (2002). Toward a theory of managing organizational conflict. International Journal of Conflict Management, 13(3), 206-235. DOI: 10.1108/eb022874

[35] Saari, L. M. \& Judge, T. A. (2004). Employee Attitudes and Job Satisfaction. Human Resource Management, 43(4), 395-407. DOI: 10.1002/hrm.20032

[36] Spector, P. E. (1997). Job satisfaction: Application, Assessment, Causes, and Consequences. Thousand Oaks, CA: Sage Publications, Inc.

[37] Stoner, J., Freeman, E. \& Gilbert, D. (1995). Managment, 6th edition. Englewood Cliffs. New Jersey: Prentice Hall, Inc.

[38] Swarnalatha, C. \& Tephillah Vasantham, S. (2014). Factors affecting job satisfaction. Indian Streams Research Journal, 4(5), 25-37. 
[39] Terason, S. (2018). The Effect of Conflict Management in Thai Public-Sector Sport Organizations on Employee Job Satisfaction and Perceived Organizational Performance. Academy of Strategic Management Journal, 17(1), 1-9.

[40] Ting-Toomey, S. (1988). Intercultural Conflicts: A face-negotiation theory. In: Y. Kim \& W. Gudykunst (Eds.), Theories in Intercultural Communication (pp. 213-235). Newbury Park, CA: Sage Publications, Inc.

[41] Ting-Toomey, S., Gao, G., Trubisky, P., Yang, Z., Kim, H. S., Lin, S.-L. \& Nishida, T. (1991). Culture, face maintenance, and styles of handling interpersonal conflict: A study in five cultures. International Journal of Conflict Management, 2(4), 275-296. DOI: 10.1108/eb022702

[42] Titov, E., Virovere, A. \& Kuimet, K. (2018). Conflict in Organization: Indicator for Organizational Values. In: Organizational Conflict (pp. 19-36). DOI: 10.5772/intechopen.75496

[43] Vujic, D. (2008). Menadžment ljudskih resursa i kvalitet: Ijudi - ključ kvaliteta i uspeha. Centar za primenjenu psihologiju, Beograd.

[44] Wang, G., Jing, R. \& Klossek, A. (2007). Antecedents and management of conflict: Resolution styles of Chinese top managers in multiple rounds of cognitive and affective conflict. International Journal of Conflict Management, 18(1), 74-97. DOI: 10.1108/10444060710759327

[45] Williams, C. (2010). Principi menadžmenta - MGMT. Data Status, Beograd.

[46] Ye, Z., Liu, H. \& Gu, J. (2019). Relationships between conflicts and employee perceived job performance: Job satisfaction as mediator and collectivism as moderator. International Journal of Conflict Management, 30(5), 706-728. DOI: 10.1108/IJCMA-01-2019-0010

Received: 2019-10-02

Revisions requested: 2020-04-29

Revised: 2021-06-24 (4 times)

Accepted: 2021-06-25

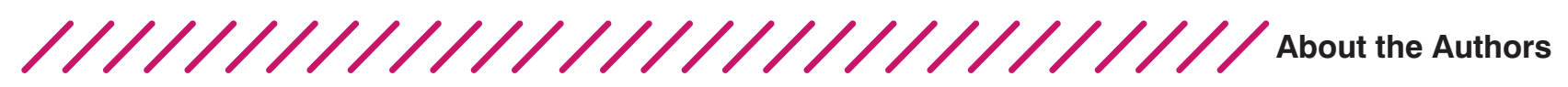

\section{Marko Pavlović \\ PE Post of Serbia, Belgrade \\ markopavlovic25101982@gmail.com, markopavlovic82@mts.rs}

Marko Pavlović is employed at the PE Post of Serbia in Belgrade. He obtained his PhD in 2021 at the Faculty of Business Studies and Law in Belgrade, Union - Nikola Tesla

University. He has participated in several international conferences and has published scientific papers in journals recognized by the Ministry of Education, Science and Technological Development of the Republic of Serbia. More than twenty scientific papers he authored have been published so far. He was elected and worked as a Teaching Assistant at

the Faculty of Economics and Engineering Management in Novi Sad, University Business

Academy in Novi Sad, during three school years. The areas of his interest are: management, human resources management, banking and customer relations.

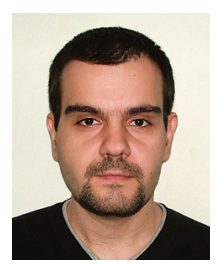

\section{Faculty of Engineering Management, Belgrade, Union - \\ PE Post of Serbia University biljana.svisic@fim.rs, bstojanovic33@yahoo.com}

Assistant Professor at the Faculty of Engineering Management in Belgrade, Union - Nikola Tesla University, and Independent Associate at the PE Post of Serbia in Belgrade. She is a member of the International Paneuropean Union based in Strasbourg, and as a delegate from Serbia participated in numerous conferences throughout Europe, attended by senior

European officials. She is a member of the Association of Business Women and

Entrepreneurs of Serbia. The main areas of her academic interest are: European integration,

Serbia's accession to the EU, socially responsible business and business communication.

She obtained her PhD in 2016 at the Faculty of Business Studies in Belgrade, Megatrend University. She defended her master thesis in 2008 at the Faculty of Management in Zaječar, Megatrend University, where she completed her basic studies in 2004. She graduated from the ICT College of Vocational Studies, University of Belgrade, in 2002. She also completed the course of diplomatic protocol at the Instituto Europeo Campus Stellae.

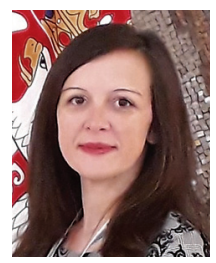


Marija Runić Ristić

Faculty of Management, Sremski Karlovci, Union - Nikola Tesla University

runic@famns.edu.rs

Assistant Professor at Faculty of Management in Sremski Karlovci, Union - Nikola Tesla University. She received her PhD from the Faculty of Technical Sciences, University of Novi Sad. Between 2015 and 2018, she was a Visiting Assistant Professor at the College of Business and Administration, American University in the Emirates Dubai, UAE. For more than 10 years she has been an active researcher supervising numerous graduate and undergraduate theses and projects. She is the author of numerous conference papers and journal articles on human resource management and management issues ranging from employment relations, organizational behaviour, ethical behaviour and corporate best practices. 